\title{
A longitudinal observational study of user's perspective of use of Copper-T-380-A inserted in immediate post partum period at a tertiary health care centre in Central India
}

\author{
Anshuli Trivedi ${ }^{1 *}$, Pradeep Kumar Kasar ${ }^{2}$, Rajesh Tiwari ${ }^{2}$, Arvind Shrama ${ }^{2}$ \\ ${ }^{1}$ Department of Community Medicine, Gandhi Medical College, Bhopal, M.P., India \\ ${ }^{2}$ Department of Community Medicine, NSCB Medical College, Jabalpur, M.P., India \\ Received: 30 September 2013 \\ Accepted: 8 October 2013 \\ *Correspondence: \\ Dr. Anshuli Trivedi, \\ E-mail: dranshulitrivedi@yahoo.com \\ (C) 2013 Trivedi A et al. This is an open-access article distributed under the terms of the Creative Commons Attribution \\ Non-Commercial License, which permits unrestricted non-commercial use, distribution, and reproduction in any \\ medium, provided the original work is properly cited.
}

\begin{abstract}
Background: The study aims to understand user's perspective \& complaints due to Copper-T-380A inserted during the immediate postpartum period and to assess the expulsion rate, voluntary removal \& mean duration of use. The study also aims to find out reasons for voluntary removal of the IUD.

Methods: A longitudinal observational was conducted in tertiary health care center in central India during July-2009 to June 2010. A total of 360 women were enrolled who had immediate post partum IUD insertion. They were interviewed within 48 hours of IUD insertion using a preformed pre tested questionnaire \& followed after $1.5,3 \& 6$ months in field visits.

Results: Of all $74.51 \%$ users continued using it upto $22.04 \pm 2.66$ weeks. The cumulative expulsion rate at the end of 6 months was $16.62 \%$. Most common interval of expulsion was after 3.6 \pm 1.5 weeks of IUD insertion. Almost $24.58 \%$ users had voluntary removal of IUD after a mean duration of $9.34 \pm 3.54$ weeks following insertion. The most common reason for voluntary removal of IUD is lower abdominal pain in $13.5 \%$. No instance of uterine perforation, sepsis or hyperpyrexia was noted.

Conclusion: Immediate postpartum IUD insertion is safe means of contraception. There is a gradual decline in the discomfort caused by an IUD with time. But there is high expulsion rate.
\end{abstract}

Keywords: Immediate postpartum period, Longitudinal observational study, Voluntary removal, Cumulative expulsion rate, Hyperpyrexia

\section{INTRODUCTION}

Presently in India only $56.3 \%$ eligible couples are effectively protected against conception by one or another family planning method. ${ }^{1}$ As per National Family Health Survey-3 data for India only $1.7 \%$ females use IUD as contraceptive. ${ }^{1}$ The latest data available for contraceptive use in India although indicates wider acceptability of the family planning services compared to the past. $^{2}$

Immediate postpartum contraception is the introduction of contraceptive within 48 hours of delivery. ${ }^{3}$ This period is the most appropriate time of introducing contraception as a woman is not pregnant. Also her motivation to use contraceptive is high. It is probably the earliest means of preventing unintended pregnancy, which is usually undiagnosed during lactation. There is an immense need for immediate postpartum contraception in developing countries with limited medical resources \& access. In developing countries institutional child birth affords a unique opportunity to provide contraception. Hence immediate postpartum contraception will help her to protect from undiagnosed \& unplanned pregnancy. 
Intrauterine contraceptive device is the most commonly used reversible method of contraception worldwide with about 127 million current users. ${ }^{4}$ Its one time application makes it users friendly. Also it has a long duration of contraception of 10 years \& its non interference with lactation. Currently IUD is generally provided in interval period or post puerperal \& not frequently during the immediate postpartum period. Initially there were availability of limited evidences of the use of IUDs in the immediate postpartum period. Also data pertaining to the user's perspective of the use of IUDs in the postpartum period is scarce. The study aims to understand the user's perspective and to identify complaints due to IUD inserted in the immediate postpartum period. The study also finds rates $\&$ means duration of continuation of use expulsion, voluntary removal and possible reasons for voluntary removal. The findings of the study are perceived to generate advocacy for use of IUDs in the immediate postpartum period as safe $\&$ effective means of contraception.

\section{METHODS}

Hence a longitudinal time series observational study was planned. This was conducted in Rani Durgavathi Hospital Jabalpur (M.P.) India during July 2009 to June 2010. Due authorization was taken from the ethics committee of NSCB Medical College Jabalpur (M.P.) India and superintendent of Rani Durgavathi Hospital Jabalpur (M.P.) to conduct this study. Informed consent was taken from all participants prior to participating in the study. A pilot study was performed to pre test questionnaire to be used in the study. During this it was observed that $30 \%$ of women delivering in institute consented for IUD insertion in the postpartum period. The response rate to the questionnaire was found to be $80 \%$. A sample size of 360 was obtained using Epi info 3.5.1 (Taking expected population as 4000, expected frequency as-30\%, at CI-95\%, Confidence limit $5 \%+20 \%$ of non responders) was obtained.

All the users were inserted IUD within 48 hours and those who consented for participating in the study were included. Those having post-partum hemorrhage (PPH), severe anemia, obstructed labor and distorted uterine cavity by fibroid or by congenital malformation and those with poor neonatal outcome were excluded from the study. Also the women who had Caesarean section were excluded as they were not inserted an IUD in the immediate postpartum period as per policy of institute.

In total 360 women who were inserted IUD in the immediate postpartum period were interviewed within 48 hours of IUD insertion using a preformed-tested questionnaire at Lady Elgin Hospital Jabalpur (M.P.). The questionnaire inquired about their contact information, socio demographic profile along with past menstrual, obstetric history. Also the history of contraceptive use prior to this pregnancy was elicited. Also whether the patient is satisfied with the use of an IUD as a contraceptive was asked. It was also inquired that whether the patient will be able to identify IUD in situ by palpation of thread in the perineum.

All the users were informed to visit the hospital after 1.5 months of IUD insertion, on a specific day at a particular time. Out of all 360 users, only 333 users reported for post puerperal health examination at Lady Elgin Hospital. During the follow up visit all the women were inquired about the presence of any complaint due to IUD \& continuation of use by palpation of IUD thread in perineum, history of spontaneous expulsion or voluntary removal of the IUD. The users were also motivated for a pelvic examination to check for the presence of an IUD in situ.

The same users were followed up prospectively after 3 and 6 months after delivery during July-2009 to June2010 through field visits \& telephonic interview. During the follow up all the women were inquired about the presence of any complaint due to IUD \& continuation of use, history of spontaneous expulsion or voluntary removal of the IUD.

All the users were traced by field visits and telephonic interview. During follow up all users could not be traced. All the users were not traceable and out of 333 users, 298 users were traced after 3 months \& 257 were traced after 6 months respectively. In total $20.55 \%$ users were lost during follow up. During follow up all the users were inquired about the same information. The confirmation of IUD in situ was based on the history of palpation of IUD in perineum by user's only. No pelvic examination was done due to practical problems (Failure to give consent by the user, lack of appropriate place, personnel \& equipment, users menstruating at time of visit).

Statistical analysis was done using MS Excel-2007 and Epi info version 3.5.1. To describe the demographic characteristics of the study participants, we used means, standard deviations, frequencies, and percentages.

\section{RESULTS}

Of all the 360 users, It was found that, $60.8 \%$ (219/360) users were primipara, $28.05 \%(101 / 360)$ users had one live issue before this delivery, $9.44 \%$ (34/360) users had to live issue before this delivery \& $1.6 \%(6 / 360)$ users had more than 2 live issues before this delivery.

In our study it was observed that $66.66 \%$ (240/360) users had no complaint during 48 hours after IUD insertion \& $33.33 \%$ (120/360) users had some discomfort after IUD insertion. Of all 360 user $13.88 \%$ (50/360) users had lower abdominal pain during 48 hours of delivery \& $7.5 \%(27 / 360)$ users had excessive bleeding per-vagina, $5.55 \%(20 / 360)$ users had pain in perineum \& $6.11 \%$ (22/360) users had a combination of two or more symptoms. No incidence of uterine perforation, hyperpyrexia or sepsis was reported. It was observed that the users who were inserted IUD within 30 minutes of 
delivery experienced less complaints compared to IUD inserted in later periods $\left(\chi^{2}=34.62 \mathrm{df}-1 \mathrm{p}-0.001\right)$.

During follow up visit after 1.5 months of IUD insertion, only 333 users reported. Out of 333 users 237 users reported of the presence of an IUD in situ by palpation of IUD thread in the perineum. Almost $14.71 \%$ (49/333) users reported spontaneous expulsion of the IUD. Out of all 49 users, $6 \%$ (20/333) gave a history of IUD expulsion within 7 days as noticed during defecation, $4.8 \%$ (16/333) confirmed that the IUD was lying too low in perineum \& so was pulled out by users but $1.5 \%(5 / 333)$ gave a history of probable expulsion as they could not feel IUD thread. Of all $24 \%$ (8/333) confirmed expelled IUD by an internal examination. It was found that $8.40 \%$ (28/333) reported voluntary removal of the IUD. It was seen that $63.60 \%$ (212/333) of users had no complaint at least 1.5 month after IUD insertion. The most common complaint was lower abdominal pain in $16.81 \%(56 / 333)$ users followed by pain in perineum by $7.20 \%(24 / 333)$ users, heavy menses in $6.30 \%(21 / 333)$ users \& $6.0 \%$ (20/333) users had a combination of two or more symptoms. All the users were motivated for pelvic examination, but out of 333 users only 294 users consented for pelvic examination IUD-in situ was found in $85.71 \%$ (252/294) users.

The users were traced 3 months after IUD insertion by field visits and telephonic interview, 21 more users could not be traced in the field visit. It was observed that $65.26 \%(171 / 262)$ users did not have any complaint. The most common complaint was lower abdominal pain in $10.68 \%(28 / 262)$ users, followed by pain in perineum $3.4 \%(9 / 262)$ users, heavy menses in $4.58 \%(12 / 262)$ users, $3.81 \%(10 / 262)$ users had abnormal vaginal discharge, dyspareunia in $1.9 \% \quad(5 / 262) \& 5.33 \%$ (14/262) users had a combination of two or more symptoms. Almost $1.90 \%$ (5/262) reported spontaneous expulsion confirmed by the history of expelled IUD. At least $5.36 \%(14 / 262)$ users reported of voluntary removal of the IUD.

After 6 months of IUD insertion, further 26 more users were non traceable. It was seen that $71.42 \%(155 / 217)$ users confirmed presence of an IUD in situ by palpation of thread. If all users $68.66 \%(149 / 217)$ users have not had any complaint. Most common complaints of all users were lower abdominal pain in $7.83 \%$ (17/217) users followed by heavy menses in $5.99 \%$ (13/217) users, $4.60 \%$ (10/217) users had abnormal vaginal discharge, $2.76 \%(6 / 217)$ users suffered from dyspareunia \& $5.99 \%$ $(13 / 217)$ users had a combination of two or more symptoms. None of the users reported spontaneous expulsion. At least $4.14 \%(9 / 217)$ users reported of voluntary removal of the IUD. There was no case of misplaced IUD.

Of all 360 users $20.55 \%$ (74/360) were not traceable. At the end of 6 months, $74.51 \%(155 / 208)$ of IUD users continued using it up to 6 months after insertion \& a mean duration of continuation of the use of IUDs is
$22.04 \pm 2.66$ weeks. The cumulative expulsion rate at the end of 6 months was $16.62 \%$ after $3.6 \pm 1.5$ weeks of insertion.

It was seen that $24.58 \%(51 / 208)$ users had voluntary removal of IUD after a mean duration of $9.34 \pm 3.54$ weeks following insertion. The most common reason for voluntary removal of IUD is lower abdominal pain in $13.5 \%(28 / 208)$ users, pain in perineum in $8.65 \%$ $(18 / 208)$, followed by heavy menses in $5.76 \%(12 / 208)$ cases. $3.84 \%(8 / 208)$ users had voluntary removal at the time of Tubectomy.

\section{DISCUSSION}

No incidence of uterine perforation, pyrexia \& infection was found. Hence the use of IUDs in the immediate postpartum period was found to be safe, these findings are similar to that stated by Thiery $\mathrm{M}$ that the immediate post partum IUD insertion was not found to be dangerous in terms or delayed uterine involution in the immediate postpartum period. ${ }^{5}$

In the current study it was found that there is a decline in complaints due to IUD after $1.5,3$ \& 6 month after IUD insertion. It was observed that lower abdominal pain was the most common complaint followed by heavy menses. This finding is similar to finding by Hubacher D. The study also concluded that the incidence of menstrual bleeding and lower abdominal pain decrease over time. ${ }^{6}$ However it cannot be proved that these complaints are due to IUD or simply due to post partum physiological discomfort.

It was observed that $74.51 \%$ of IUD users continued using it up to 6 months after insertion. The results found in study differ from results obtained, in a study by Celen $S \&$ et al in which it was found that the continuation rates after postpartum insertion of IUD after 6 months of IUD insertion were relatively high, of $87.6 \% .^{7}$ This could be due to lack of motivation to user to use contraceptive. The results of continuation of use are based on the history of palpation of IUD thread and not on the basis of pelvic examination.

It was seen that the expulsion rate of the study is higher than the standard spontaneous expulsion rate found out in a study by Celen $S$ \& et al, in which 1-year cumulative expulsion rate was found to be $12.3 \%$. The spontaneous expulsion rate was higher than expulsion after interval IUD insertion which is $5 \%$. $^{7}$

It was observed that in the study that the most common reason for voluntary removal of IUD is pain in lower abdomen and perineum, followed by heavy menses. This finding differs from the finding of a study done by ESHRE Capri Workshop Group in Milan in which heavy bleeding during menses is the most common reasons for voluntary removal of the IUD. ${ }^{8}$ 
Hence it can be concluded that immediate post partum IUD insertion is found to be safe from this study \& there is low risk to the users despite its high expulsion rate. It is suitable for the developing countries as presently there is an increased motivation towards institutional delivery. This opportunity of contact of women of reproductive age group with health personnel can be used for availing contraception.

\section{ACKNOWLEDGEMENTS}

The authors would like to thank P. R., the state coordinator UNFPA Madhya Pradesh for giving this project for study to the department, to all faculty members \& residents of the Department of Community Medicine, NSCB Medical College Jabalpur (M.P) for their intellectual inputs in data collection, analysis \& interpretation and to Dr. Neerja Dubey, Superintendent and all personnel at Lady Elgin hospital Jabalpur (M.P.) India for their support in planning \& organizing study.

\section{Funding: None}

Conflict of interest: None declared

Ethical approval: The study was approved by the ethics committee of NSCB Medical College Jabalpur, M.P., India

\section{REFERENCES}

1. Key indicators for India from NFHS-3.Source-India International Institute for Population Sciences (IIPS) Mumbai cited since 2009 available from URL(http://www.rchiips.org/nfhs/pdf/India.pdf).
2. Usher Ram. Contraceptive Use among Young Married Women in India This paper has been prepared for presentation at the International Conference on Family Planning: Research and Best Practices to be jointly organized by Bill and Melinda Gates Institute for Population and Reproductive Health, John Hopkins University, School of Public Health, USA, Maker ere University, School of Public Health during November 15-18, 2009 at Munyonyo, Uganda.

3. Farrell, Douglas Haber-Module-13 -Post partum\& post abortion contraception- Medical services. Pathfinder publication February-1998; 5.

4. Anita L. Nelson. Intrauterine contraceptives In: Gynecology \& Obstetrics CD.ROM 2004 edi Maryland: Lippincott Williams and Wilkins; 2004; Chapter 16.

5. Theiry M. Immediate postpartum insertion of IUDs. IPPF Med Bull. 1981 Jun;15(3):1-2.

6. Hubacher D, Chen PL, Park S- Side effects from the copper IUD: do they decrease over time? Contraception. 2009 May;79(5):356-62.

7. Celen S, Möröy P, Sucak A, Aktulay A, Danişman N. Clinical outcomes of early postplacental insertion of intrauterine contraceptive devices. Contraception 2004 Apr;69(4):279-82.

8. ESHRE Capri Workshop Group. Intrauterine devices and intrauterine systems. Contraception. 2008 Oct;78(4):290-3.

DOI: $10.5455 / 2320-1770 . i j r \operatorname{cog} 20131220$

Cite this article as: Trivedi A, Kasar PK, Tiwari

R, Shrama A. A longitudinal observational study of user's perspective of use of Copper-T-380-A inserted in immediate post partum period at a tertiary health care centre in Central India. Int J Reprod Contracept Obstet Gynecol 2013;2:591-4. 